\title{
Assessing the risk of loss and damage: exposure, vulnerability and risk to climate-related hazards for different country classifications
}

\author{
Joern Birkmann* \\ Institute for Environment and Human Security, \\ United Nations University, \\ UN Campus Platz der Vereinten Nationen 1, \\ 53113 Bonn, Germany \\ Email: birkmann@ehs.unu.edu \\ *Corresponding author

\section{Torsten Welle} \\ Institute for Environment and Human Security, \\ United Nations University, \\ UN Campus Platz der Vereinten Nationen 1, \\ 53113 Bonn, Germany \\ Email: welle@ehs.unu.edu
}

\begin{abstract}
Preventing and reducing loss and damage due to extreme events is an important topic for the international community, especially in the context of climate change negotiations and disaster risk reduction. The paper outlines the latest state-of-the-art approaches to assess loss and damage and the risk of loss and damage. Against this background, a more in-depth analysis is provided on how to assess the risk of loss and damage in different country groups (i.e., World Bank income groups) focusing on selected slow- and sudden-onset climate-related hazards using the concept of the WorldRiskIndex. The results underscore that the risks of loss and damage for low- and high-income countries are significantly different, but also that global risk patterns differ significantly regarding sudden-onset versus slow-onset hazards. In the first step of analysis, the results show that not only does exposure to extreme events influence the risk of loss and damage, but equally important are the vulnerability and adaptive capacities of societies. The second step of analysis shows that target-oriented adaptive strategies to the various impacts of climate-related hazards are crucial in reducing the respective risk of loss and damage.
\end{abstract}

Keywords: loss; damage; risk-assessment.

Reference to this paper should be made as follows: Birkmann, J. and Welle, T. (2015) 'Assessing the risk of loss and damage: exposure, vulnerability and risk to climate-related hazards for different country classifications', Int. J. Global Warming, Vol. 8, No. 2, pp.191-212.

Biographical notes: Joern Birkmann received his $\mathrm{PhD}$ in Spatial Planning from the Dortmund University and his Post-doctoral in Geography (Habilitation) from the University of Bonn, Department of Geography. He has extensive expertise in the fields of spatial and urban development, vulnerability 
and risk assessment. He is IPCC lead-author for the fifth IPCC Assessment Report (AR5) and also for the IPCC Special Report 'Managing the Risk of Extreme Events and Disasters to Advance Climate Change Adaptation'. Moreover, he is a member of the Science Committee of the international program Integrated Research on Disaster Risk (IRDR).

Torsten Welle received his $\mathrm{PhD}$ in Geography and his Master of Science in Geography, Soil Science and Economics, both from the University of Bonn. He has a broad expertise in the fields of remote sensing, geographical information systems (GIS) and in climatology. His $\mathrm{PhD}$ was concerned with modelling of rainfall pattern in Namibia. During his work at the University of Bonn, he was working within the multidisciplinary collaborative research centre ACACIA in Africa. At UNU-EHS, he is a main researcher within key index and indicator projects, such as the WorldRiskIndex or the Coast at RiskIndex.

\section{Introduction}

Discourse regarding loss and damage due to extreme events is not new; however, it has gained particular attention in the context of the ongoing climate change adaptation (CCA) negotiations, especially at the Cancun Climate Change Conference of Parties (COP16) in 2010. In this regard, a work program on loss and damage associated with the impact of climate change on developing countries was established, and in the coming years new mechanisms and institutional arrangements for addressing loss and damage in the context of climate change are being developed in order to more systematically address loss and damage due to climate change (UNFCCC, 2011b). The issue of loss and damage is dealt with in climate change negotiations under three thematic areas:

1 assessing the risk of loss and damage associated with the adverse effects of climate change and current knowledge

2 developing a range of approaches to address loss and damage associated with the adverse effects of climate change, including any impact related to extreme weather and slow-onset events

3 the role of the United Nations Framework Convention on Climate Change (UNFCCC) in enhancing the implementation of approaches to address loss and damage associated with the adverse effects of climate change (UNFCCC, 2011a).

Against this background the paper is focusing especially on the assessment of the risk of loss and damage associated with climate-related hazards (thematic area 1). Additionally, this approach offers the opportunity to assess the risk of loss and damage based on the diverse impact of climate change such as slow- and sudden-onset climate-related hazards (thematic area 2). Based on the results of our own research, this paper emphasises the need to consider target-oriented adaptive strategies related to slow- and sudden-onset climate-related hazards, taking into account the range of developmental stages of countries represented by the income groups classified according to the World Bank. In the first step, an overview of different perspectives is provided, which focuses on different measurement approaches for loss and damage. In the second step, a concrete assessment approach is presented - the WorldRiskIndex - which underscores the need to 
move from a retrospective, reactive and narrow approach to addressing loss and damage to a broader understanding of the multiple facets that determine the 'risk' of loss and damage. In order to move from a purely conceptual discussion to challenges related to assessing and ranking countries most at risk of suffering loss and damage due to climate change, a modified version of the concept of the WorldRiskIndex will be presented and applied in more detail.

Hence, the index used herein is based on the concept of the WorldRiskIndex (Birkmann et al., 2011; Welle et al., 2013), which accounts for the physical exposure to climate-related or climate-influenced hazards such as storms, floods, rising sea levels and droughts; however, it also stresses the fundamental importance of vulnerability by assessing the susceptibility, coping capacity and adaptive capacity of countries and societies exposed to these hazards. The results of the WorldRiskIndex are further differentiated according to the development status of countries based on the World Bank's income classification groups. This analysis reveals among other issues that important differences can be found between countries and income groups, but also within countries in specific income groups and their risk profiles due to climate-related slow-onset hazards such as sea-level rise and sudden-onset hazards such as floods.

The differentiation between the exposure to climatic stressors on the one hand and the vulnerability of societies on the other clearly emphasises that approaches for addressing loss and damage need to reduce exposure, but even more importantly need to reduce societal vulnerabilities. Based on the findings of the country rankings and global risk profiles, we conclude that addressing the risk of loss and damage requires more precise risk reduction and adaptation policies that take into account the different levels of exposure and vulnerability as well as the varying global risk patterns in terms of slowonset and sudden-onset hazards. Finally, the index also raises questions about the appropriateness of national adaptation and risk reduction strategies in countries where vulnerability patterns are also severely influenced by failures in governance.

\section{Different understandings of assessing (the risk of) loss and damage}

A review of existing approaches to assess the risk of losses and damages due to hazards related to climate change is a challenge in itself, since the definition of what encompasses loss and damage as well as how these characteristics can be assessed is already controversial. ${ }^{1}$ Hence, a comprehensive climate 'loss and damage' assessment methodology has not yet been developed. Interestingly, it is still an open question as to whether climate change negotiations and the related work program on 'loss and damage' actually focus on 'loss and damage' or on the 'risk of loss and damage', which carry different perspectives in terms of assessments and priorities. While the assessment of 'loss and damage' focuses on the experienced loss (with a post-disaster or crisis focus), the 'risk of loss and damage' refers to an assessment of the potentiality and likelihood that certain people, communities or nations will face major loss and damage (pre-disaster perspective).

When examining current international discourse, we can differentiate at least two major schools of thought: the disaster risk reduction (DRR) community and the school of CCA. Although these schools and research communities have thus far developed primarily in parallel, the Intergovernmental Panel on Climate Change (IPCC, 2012) special report, Managing the Risks of Extreme Events and Disasters to Advance Climate 
Change Adaptation (SREX), is a good example of the newly established cooperation and joint work between both communities. Within the DRR and CCA communities, various frameworks and conceptualisations on how to assess risk and vulnerability were developed, including quantitative and qualitative assessment methodologies (see, e.g. Wisner et al., 2004; Birkmann, 2013; International Federation of the Red Cross and Red Crescent Societies, 2008; IPCC, 2012). While risk is seen as the product of the interaction between an extreme event or hazard and the vulnerability of a society or community, the term vulnerability is understood as a predisposition to be affected (see, e.g., IPCC, 2012) or as an internal risk factor (see Birkmann, 2013). In this regard, the hazard or the physical event linked to climate change is seen as an external factor to the society or system exposed. In the early 1990s, Burton et al. stressed that disaster loss and damage is caused by the interrelation between hazardous events and the characteristics of the exposed elements that are susceptible to damage (see Burton et al., 1993). The new framework presented in the SREX report (IPCC, 2012) and also the latest assessment report of the IPCC working group II (IPCC, 2014) underscores that (disaster) risk is determined by the interaction between extreme weather events which are influenced by anthropogenic climate change and climate variability on the one hand and the vulnerability and exposure of societies influenced by socio-economic development processes on the other (see Figure 1). The report also emphasises that a risk perspective is essential in order to be able to effectively address the potential negative consequences of extreme events due to climate change (see IPCC, 2012). Consequently, this paper argues that addressing the risk of loss and damage in the context of climate change requires an improved understanding of the social construction of vulnerability and exposure as well as the potential changes and magnitude of climate-related hazards.

Figure 1 Systematisation of climate change related events, vulnerability, exposure, risk and development (see online version for colours)

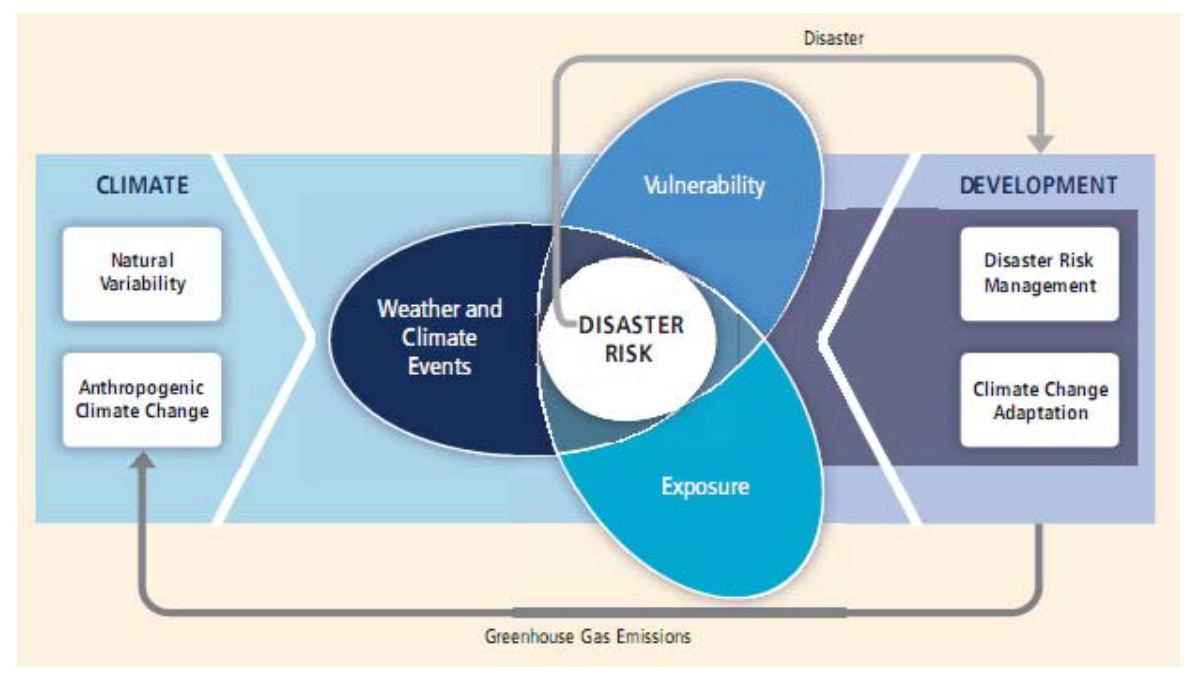

Source: IPCC (2012)

Some readers could argue that the assessment of the risk of loss and damage is significantly different from approaches that aim to assess loss and damage due to climate change. Even though this is the case and most documents in the UNFCCC work program 
on loss and damage refer primarily to the goal to reduce loss and damage, this paper argues that adaptive strategies in the context of loss and damage reduction must deal with risks rather than past impact (that is, experienced loss and damage). This is also supported by the various findings documented in the fifth IPCC assessment report (see IPCC, 2014).

Furthermore, the Economic Commission for Latin America and the Caribbean (ECLAC) (2003) emphasises that loss and damage assessment is a part of risk assessment and its goal is to measure (mostly in monetary terms) the impact of disasters on society, the economy and the environment of the affected country or region. In addition, Handmer et al. (2005) describe loss and damage assessment as an analysis of losses from past events or the estimation of future losses and damages focusing on the quantification of direct and indirect impacts. However, this paper argues that, beyond this economic dimension, there is a wider range of less measurable impacts including those related to social vulnerability and resilience, which are difficult to monetise.

The Fukushima crises after the Tohoku earthquake and the subsequent tsunami in Japan provide an example of how loss and damage not only brought about monetary losses, but also resulted in the loss of trust in institutions particularly as this related to the capacity of the government and the private sector (in particular, the company TEPCO) to manage such crises effectively (Reb et al., 2012). Even where the monetisation of such impacts is possible, a large degree of uncertainty remains.

Interestingly, the Australian Emergency Management Agency’s (EMA) guidelines on assessing disaster-related loss allow for the differentiation of direct and indirect losses as well as distinguishing between tangible and intangible items (EMA, 2002). An improved consideration of intangible items and indirect losses is also a major challenge for CCA strategies in the context of extreme events. Figure 2 presents an overview of selected approaches to assess loss and damage and risk assessment within the CCA and DRR communities.

Figure 2 Overview of different approaches, methodologies and tools for loss and damage assessment (see online version for colours)

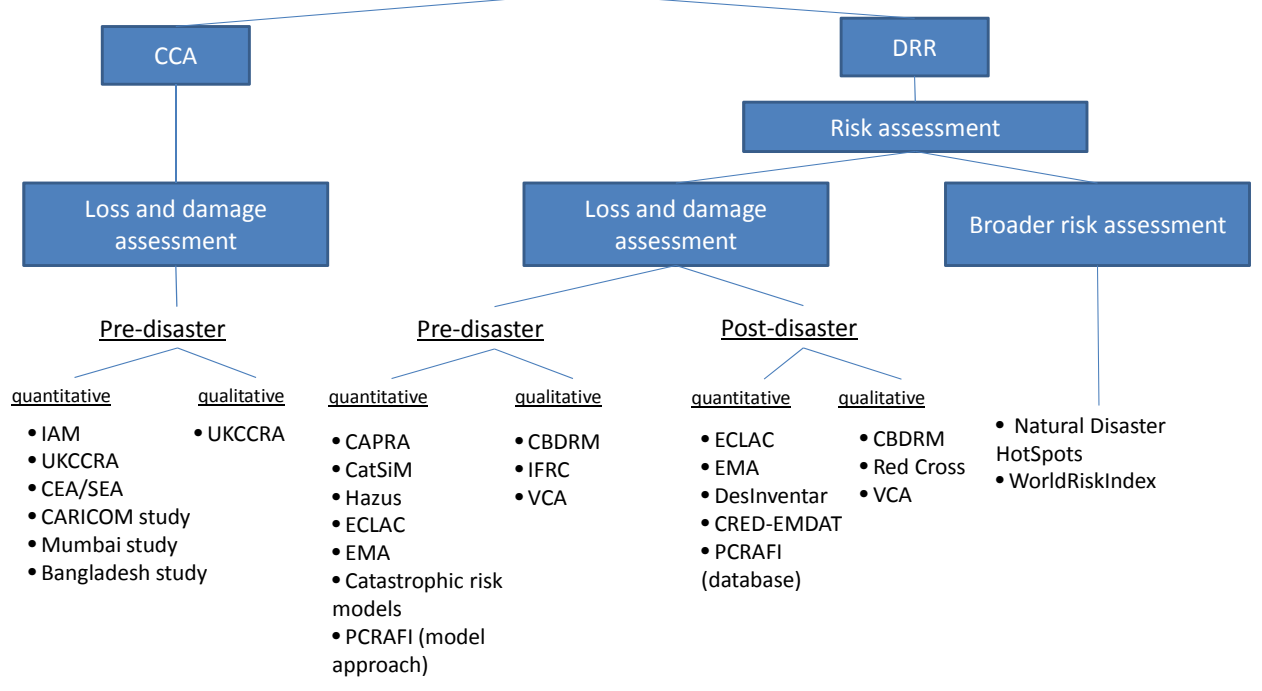


Even though a more in-depth examination of the different approaches to assess tangible versus intangible aspects of loss and damage would be possible, this paper aims to provide new insights into global patterns of the risk of loss and damage using the concept of the WorldRiskIndex and its application to the level of nation states.

\section{The WorldRiskIndex: concept, data and methods}

The following section provides an overview of the concept of the WorldRiskIndex (see Birkmann et al., 2011; Welle et al., 2013) and its modification in the context of risks to climate related hazards. Thereafter, the index is applied using global data which is freely available. These data sets allow for the exploration of differential exposure patterns to slow- and sudden-onset hazards influenced by climate change within various country classes based on the World Bank's income groups. The WorldRiskIndex (Birkmann et al., 2011; Welle et al., 2012, 2013) encompasses a new approach and methodology to assess the risk of people facing major damages and losses in the context of natural hazards and extreme events. The concept is based on the understanding that the risk of loss and damage due to climate-related hazards is not caused solely by external forces and natural phenomena such as floods or droughts, but also by the vulnerability of a society or community exposed to these phenomena. Vulnerability as used here refers to defencelessness and a predisposition to be negatively affected by such hazards. It builds upon a newly formed consensus and the framing of risk and vulnerability outlined in the IPCC SREX report (see IPCC, 2012). In this regard, greater emphasis is also given to the exploration of the structural characteristics of a society linked, for example, to questions of governance and access to resources, as well as key societal conditions such as the number of people living in poverty or the percentage of the population that is undernourished.

The index follows a modular structure that combines hazard exposure and vulnerability data. While the hazard exposure assessment also accounts for the frequency of hazards, the vulnerability assessment in the WorldRiskIndex focuses on three key parameters:

1 susceptibility, which means that societies or communities have deficiencies and limited capacities to deal with adverse events

2 coping capacities, which describe the capacity to deal with the direct impact and consequences of an extreme event

3 adaptive capacities, which encompass elements that help to build the capacity to deal with extreme events and slower changes in the medium and longer terms (see Birkmann et al., 2011; Welle et al., 2012, 2013).

In addition, adaptive capacities allow for the promotion of transformations and help a system to change, while coping capacities enable a system to survive and maintain its structures as they exist.

In this regard, the concept of the WorldRiskIndex is clearly based on the theoretical understanding of risk within the natural hazards and disaster risk reduction community 
and the newer framework discussed in the climate change community (see UN/ISDR, 2004; Wisner et al., 2004; Birkmann, 2013; IDEA, 2005; IPCC, 2012). Within the assessment approach of the WorldRiskIndex, actual risk is seen as a product of the interaction between vulnerability and hazard exposure; however, hazard exposure also accounts for the frequency of various hazards. In addition, vulnerability is further differentiated into susceptibility, coping and adaptive components which are combined through simple addition. In contrast, the risk values are calculated through the multiplication of hazard exposure and vulnerability. Hence, we assume that, if hazard exposure or vulnerability is zero, then the level of risk will also be zero. The multiplication also means that exposure is quite influential on the overall risk score. Compared to the original application of the WorldRiskIndex, the paper here includes a modified version of the index in terms of focusing solely on climate-influenced hazards (that is, storms, sea-level rise, droughts and floods). In addition, the paper differentiates risk profiles according to World Bank income groups that systematise countries according to their income levels (Table 1). These country groups can provide some additional insights into the specific risk patterns of, for example, high- and low-income countries. In addition, they show that risk patterns differ significantly within these various income groups and between countries primarily exposed to sudden-onset versus slow-onset climate-influenced hazards.

\subsection{Application of the WorldRiskIndex}

The WorldRiskIndex is calculated based on 28 indicators: five refer to exposure representing the natural hazard sphere and 23 correspond to the societal sphere comprising susceptibility, coping capacity and adaptive capacity (Birkmann et al., 2011; Welle et al., 2012, 2013). Figure 3 provides a detailed overview of the concept of the WorldRiskIndex and its respective components and indicators. Each of the four components includes suitable indicators, while the three components related to vulnerability - namely, susceptibility, coping capacity and adaptive capacity - are divided into sub-categories such as nutrition, government and authorities as well as education and research (see bold headings over the individual indicators). Each indicator within the four components is labelled with capital letters representing the variables which are relevant for the calculation of each component [see Figure 3 and equations (1)-(8)].

The data source for all indicators applied to the index can be found in various global databases that are publicly accessible (for further details, visit http://www.worldriskreport.com/Indicators.390.0.html). For aggregation, all indicators are transformed into values of 0 and 1 using various methods such as the min-max normalisation and $\log (\ln )$ transformation. According to each component in Figure 3, individual indices are calculated and combined to determine the WorldRiskIndex (see Sections 3.2.1-3.2.5) related to natural hazards influenced by climate change, which are determined in the second step which focuses on a spatial analysis using the quantile classification method within ArcGIS 10. 
Figure 3 Components of sub-categories and selected indicators for the WorldRiskIndex related to climate-related hazards

\begin{tabular}{|c|c|c|c|}
\hline 1. Exposure & 2. Susceptibility & 3. Coping Capacity & 4. Adaptive Capacity \\
\hline $\begin{array}{l}\text { EXPOSED POPULATION } \\
\text { WITH REGARD TO } \\
\text { A) Cyclones (sudden) } \\
\text { B) Floods (sudden) } \\
\text { C) Droughts (slow) } \\
\text { D) Sea level rise (slow) }\end{array}$ & $\begin{array}{l}\text { NUTRITION } \\
\text { A) Percentage of undernourished } \\
\text { population } \\
\text { PUBLIC INFRASTRUCTURE } \\
\text { B) Population without access to } \\
\text { improved sanitation } \\
\text { C) Population without access to } \\
\text { clean water } \\
\text { PovERTY AND DEPENDENCIES } \\
\text { D) Dependency ratio (proportion of } \\
\text { individuals under } 15 \text { and over } 65 \\
\text { years compared with the working } \\
\text { population) } \\
\text { E) Extreme poverty (population } \\
\text { living on less than US\$1.25 (live } \\
\text { PPPS) per day) } \\
\text { ECONOMIC CAPACITY AND INCOME } \\
\text { F) Gross Domestic Product per } \\
\text { capita (Purchasing Power Parity) } \\
\text { G) Gini-Index }\end{array}$ & $\begin{array}{l}\text { GOVERNMENT AND } \\
\text { AUTHORITIES } \\
\text { A) Corruption Perception } \\
\text { Index } \\
\text { B) Failed States Index } \\
\text { MEDICAL SERVICES } \\
\text { C) Number of physicians per } \\
10.000 \text { population } \\
\text { D) The number of hospital } \\
\text { beds per } 10.000 \\
\text { population } \\
\text { ECONOMIC CovERAGE } \\
\text { E) Insurance (except life } \\
\text { insurance) }\end{array}$ & $\begin{array}{l}\text { EDUCATION AND RESEARCH } \\
\text { A) Adult literacy rate } \\
\text { B) Combined gross school enrolment } \\
\text { (rate of school-aged children in } \\
\text { primary, secondary and tertiary } \\
\text { educational institutions) } \\
\text { GENDER EQUITY } \\
\text { C) Gender parity in education (in } \\
\text { primary, secondary and tertiary } \\
\text { educational institutions) } \\
\text { D) Percentage of female } \\
\text { representatives in the National } \\
\text { Parliament } \\
\text { ENVIRONMENTAL STATUS / EcosYSTEM } \\
\text { PROTECTION } \\
\text { E) Water resources } \\
\text { F) Protection of biodiversity and } \\
\text { habitats } \\
\text { G) Forest Management } \\
\text { H) Agricultural Management } \\
\text { INVESTMENT } \\
\text { I) Life expectancy at birth } \\
\text { J) Private health expenditure } \\
\text { K) Public health expenditure }\end{array}$ \\
\hline
\end{tabular}

Note: Capital letters are used to label variables used in equations (1)-(8).

Source: Own figure

\subsubsection{Exposure}

Exposure is defined as those entities such as people, resources, infrastructures, goods, services or ecosystems exposed and prone to be affected by a natural hazard event (Birkmann et al., 2011). In this paper, the frequency of such hazards (floods, droughts and storms) is also taken into account. The focus, therefore, is on the annual average percentage of people exposed per country facing climate-related hazards such as sudden-onset hazards like storms and floods and slow-onset hazards like droughts and sea-level rise. The analysis of hazard exposure is based on data from the PREVIEW Global Risk Data Platform (http://preview.grid.unep.ch) of the United Nations Environment Programme (UNEP) and data from the University of Kansas. The data records on physical exposure in the PREVIEW Platform include the number of persons per spatial unit who are exposed to floods, droughts and storms (cyclones) on average per year per country. A different approach was used for the calculation of exposure due to sea-level rise, since this is a potential exposure which cannot yet be expressed in the average population exposed per year. Thus, the data on global sea-level rise by one metre is based on data from the Center for Remote Sensing of Ice Sheets (CReSIS, 2011) of the University of Kansas. This was combined and intersected with data regarding the population distribution based on the Global Rural-Urban Mapping Project (GRUMP) data set provided by the Center for International Earth Science Information Network (CIESIN et al., 2012). This, in turn, resulted in the calculation of the number of people (with 2010 as the base year) that would be affected by a one-metre sea-level rise in the year 2100 . Exposure to sea-level rise is only half-weighted as is drought exposure. According to Peduzzi et al. (2009), drought exposure calculations are very complex and carry a high uncertainty; consequently, a low weighting is justified. In addition, the exposure to sea- 
level rise is a gradual process and exposure will increase in the coming decades until 2100. Therefore, the influence of the exposure data must be reduced due to its long-term nature (lower weighting). This means that, by contrast, flood and cyclone exposure were weighted normally. Finally, all exposed people were added together and divided by the population of their country [see equation (1)]. To differentiate between sudden- and slowonset climate-related hazards, equation (2) was applied to the calculation of the people exposed to floods and cyclones, whereas equation (3) resulted in the figures for exposure related to slow-onset hazards such as droughts and sea-level rise.

$$
\begin{aligned}
& \text { Exposure }(E)_{\text {per country }}=\frac{A+B+(0.5 * C+D)}{\text { population number }} \\
& E_{\text {sudden onset }}=\frac{A+B}{\text { population number }} \\
& E_{\text {slow onset }}=\frac{(0.5 * C+D)}{\text { population number }}
\end{aligned}
$$

\subsubsection{Susceptibility}

Susceptibility $(S)$ refers to selected structural characteristics of a society and their framework conditions which make a society, social group or community more prone to being negatively affected by an extreme or non-extreme event or hazard. This means that susceptibility is seen as the likelihood of experiencing harm or damages due to the occurrence of a hazardous event. The component is operationalised into four sub-categories and their respective indicators:

1 nutrition

2 public infrastructure

3 poverty and dependencies

4 economic capacity and income distribution (Birkmann et al., 2011; Welle et al., 2012, 2013).

The weightings for the calculation of the susceptibility index were completed according to equation (4) as follows (see Figure 3):

$$
\begin{aligned}
\text { Susceptibility }(S)= & (1 / 7 * A)+(2 / 7 *(0.5 *(B+C))) \\
& +(2 / 7 *(0.5 *(D+E)))+(2 / 7 *(0.5 *(E+F)))
\end{aligned}
$$

\subsubsection{Lack of coping capacity}

Coping capacities comprise all of the means available to societies and exposed entities used to reduce the negative impact of natural hazards and climate change through direct action and resources. Thus, coping includes the available capacities that may be relevant for minimising damages during the occurrence of a hazardous event (Birkmann et al., 2011; Welle et al., 2012, 2013). The overall goal of coping is to ensure the functioning of 
a system and to maintain its structure as is in contrast to the notion of adaptation is linked to capacities to transform a system. Coping capacities encompass, for example, medical services and material coverage in addition to the framework conditions of a country described through the functioning of governments and authorities. This may also be expressed in negative terms as in the case of fragile and failed states, or relate to the availability of insurance in order to cope with economic damages. The specific weightings are show in equation (5).

$$
\begin{aligned}
\text { Coping capacity }(C C)= & (0.45 *(0.5 *(A+B))) \\
& +(0.45 \cdot(0.5 *(C+D)))+(0.1+E)
\end{aligned}
$$

Lack of coping capacity $($ LoCC $)=1-C C$.

\subsubsection{Lack of adaptive capacity}

Adaptive capacities are seen as long-term measures which enable a society to change and transform current structures in order to live with environmental and societal changes in the long run without facing major harm, loss and/or damage. Components of adaptive capacities are linked to, for example, education and research capacities, gender equity, environmental status and ecosystem protection and investments. For a detailed discussion regarding the differentiation between coping and adaptation, see Lavell et al. (2012) and Birkmann et al. (2010). These four sub-categories (see Figure 3) provide an initial data set which can be used to estimate the capacities of a society to address the negative impact of natural hazards and climate change in the future in the medium and long terms. The calculations for the adaptive capacity and the lack of adaptive capacity were carried out according to equations (7) and (8).

$$
\begin{aligned}
\text { Adaptive capacity }(A C)= & (0.25 *(0.5 *(A+B)))+(0.25 *(0.5 *(C+D))) \\
& +(0.25 *(0.25 *(E+F+G+H))) \\
& +(0.25 *(1 / 3 *(I+J+K)))
\end{aligned}
$$

Lack of adaptive capacity $($ LoAC $)=1-$ AC.

\subsubsection{Calculation of vulnerability and risk related to sudden- and slow-onset hazards}

After each index is developed [see equations (1)-(8)], the final risk index is calculated using equation (9). The differentiation in risk related to sudden-onset climate-related hazards is based on equation (10), while equation (11) is used to calculate the risk associated with slow-onset climate-related hazards. In this context, vulnerability is defined as the sum of susceptibility, a lack of coping capacities and a lack of adaptive capacities.

$$
\begin{aligned}
& \text { WorldRiskIndex (climate hazards })_{\text {total }}=E *(1 / 3 *(S+\text { LoCC }+ \text { LoAC })) \\
& \text { WorldRiskIndex }(\text { climate hazards })_{\text {sudden }}=E_{\text {sudden }} *(1 / 3 *(S+\text { LoCC }+ \text { LoAC }))
\end{aligned}
$$




$$
\text { WorldRiskIndex }(\text { climate hazards })_{\text {slow }}=E_{\text {slow }} *(1 / 3 *(S+\operatorname{LoCC}+\operatorname{LoAC}))
$$

Although the WorldRiskIndex stresses that risk is mainly determined by societal vulnerabilities, the differentiation according to the various types of hazards might allow us to explore whether or not risk patterns also differ in terms of hazard profiles in different country classes (based on World Bank, 2013) such as low- and high-income countries. This differentiation of the WorldRiskIndex based on income groups and hazard types can at least provide some insight as to whether this differentiation is important or rather insignificant for the risk profile of particular regions.

\subsubsection{Differentiation of the WorldRiskIndex into socio-economic country classes}

The differentiation of the analysis of the WorldRiskIndex into four country groups is related to the World Bank analytical classification presented as the World Development Indicators and is based on the gross national income (GNI) per capita converted to United States dollars using the World Bank Atlas method (World Bank, 2013). The classification properties for the individual country groups are presented in Table 1 and are also shown in the Appendix as Figure S1.

Table 1 Country groups based on the World Bank classification

\begin{tabular}{lcc}
\hline World Bank analytical classification & $\begin{array}{c}\text { GNI per capita in } \\
\text { US dollars (US\$) } \\
\text { (year: 2011) }\end{array}$ & $\begin{array}{c}\text { Number of countries } \\
\text { based on 173 } \\
\text { WorldRiskIndex countries }\end{array}$ \\
\hline Low-income countries (L) & $\leq$ US \$1025 & 33 \\
Lower middle-income countries (LM) & US \$1,026-US \$4,035 & 49 \\
Upper middle-income (UM) & US \$4,036-US \$1,2475 & 45 \\
High-income (H) & $>$ US \$1,2475 & 46 \\
\hline
\end{tabular}

Source: World Bank

\section{Results and findings}

\subsection{Results of the climate-related WorldRiskIndex}

According to the data available, it was possible to calculate the index for 173 countries based on the information related to the exposure of people in different countries to sudden- and slow-onset climate-related hazards and to information related to vulnerability. Finally, the exposure indices were combined with the vulnerability index to obtain three different climate-related WorldRiskIndices for the overall risk of climate influenced hazards. Figure 4 shows the results for slow- and sudden-onset exposure as well as slow- and sudden-onset risk. The maps for vulnerability, overall exposure and overall risk can be found in the Appendix (Figure S2). For the spatial analysis and the development of maps, all calculated indices were divided into five classes using the quantile classification method, which is integrated into the ArcGIS 10 software program. Therefore, each class contains an equal number of features. Based on the calculated values, each class is also described in a qualitative way, exemplified by the following classification: very high, high, medium, low and very low. Interestingly, the results show 
significant differences between the highly exposed countries in terms of sudden-onset and slow-onset hazards. Slow-onset hazards, such as droughts and sea level rise, carry a particular influence on coastal countries such as Indonesia and Vietnam and sub-Saharan countries that are known to experience droughts. By contrast, the exposure of people to sudden-onset hazards is particularly high in countries such as India and China and those situated in North America and the Caribbean. Although some countries such as Italy or the UK face a high exposure to slow-onset hazards, they are able to reduce their risk of loss and damage - e.g., the risk of the loss of life - through very low vulnerability values (see the vulnerability map in the Appendix as Figure S2). In addition, the opposite trend is observable, where countries such as India or Madagascar with low exposure (slow onset) values, increase their risk due to a higher vulnerability.

Figure 4 Exposure of people to (a) slow and (b) sudden-onset hazards (combined with the vulnerability see Appendix Figure S2) and risk levels to slow-onset (c) and sudden-onset (b) hazards based on the WorldRiskIndex concept (see online version for colours)

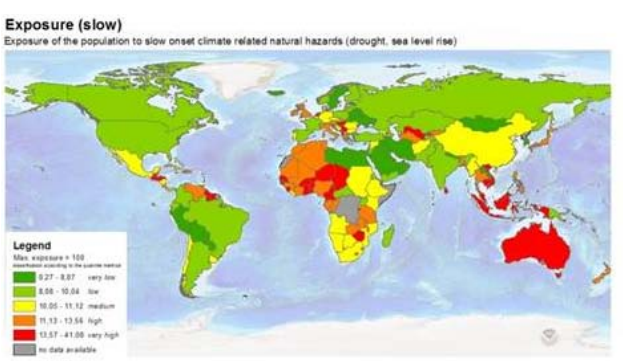

(a)

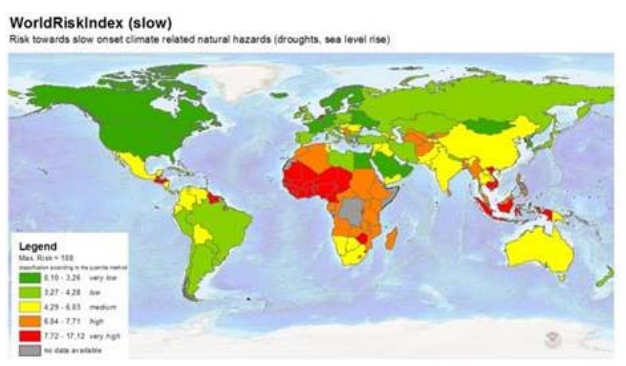

(c)

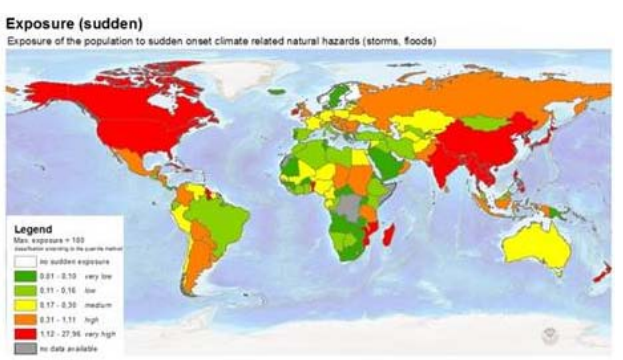

(b)

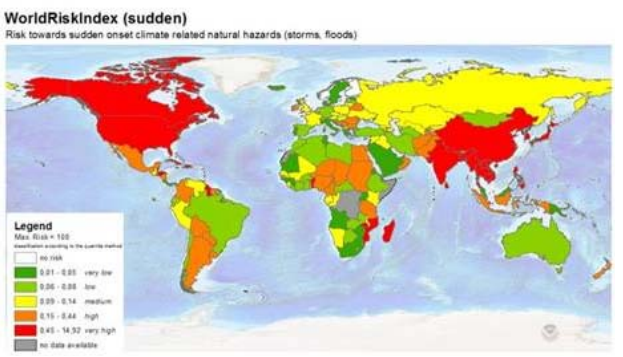

(d)

Source: Own figure

\subsection{Combining four country groups with the WorldRiskIndex and ranking results}

In a subsequent step, we examined the WorldRiskIndex value with respect to different socio-economic country classification groups provided by the World Bank. Figures 5 and S3 (see Appendix) show the results of the WorldRiskIndex with respect to climate-related hazards in combination with the four World Bank country classification groups: 
a low-income countries

b lower middle-income countries

c upper middle-income countries

d high-income countries.

(The maps for lower middle- and upper middle-income country groups appear in the Appendix as Figure S3.) The maps in Figure 5 show the risk for high-income countries (low-income countries) related to slow-onset hazards such as droughts and sea-level rise (left) in Figure 5(a) [Figure 5(b)], and to sudden-onset climate-related hazards (right) such as floods and cyclones. The map shows that not only do major differences exist between low- and high-income countries related to slow- and sudden-onset hazards, but also within each income group. The USA, for example, is classified as very low risk regarding slow-onset hazards yet as very high risk for sudden-onset hazards; the same pattern is found for Japan which is classified as low risk regarding slow-onset hazards, but very high risk with respect to sudden-onset hazards. Interestingly, Mauretania shows a very low risk related to sudden-onset hazards, but a very high risk related to slow-onset hazards especially droughts.

Figure 5 Climate-related risk in the (a) high and (b) low income country classifications groups differentiated into (left) slow- and (right) sudden-onset hazards (see online version for colours)
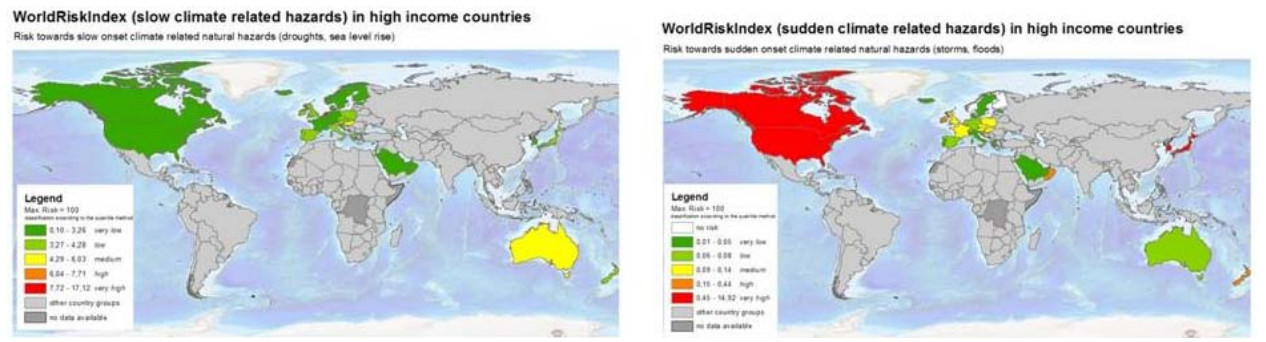

(a)
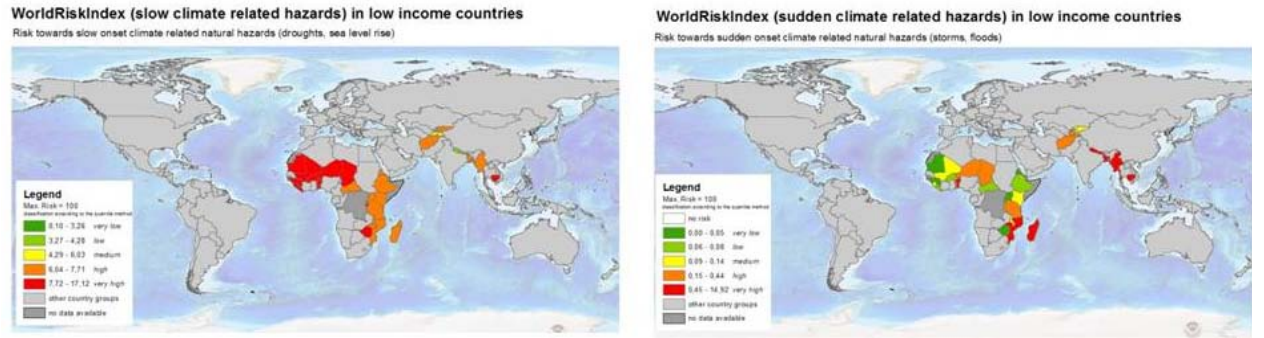

(b)

Source: Own figure

The data analysis related to calculating percentiles based on risk values and individual country groups (Table 2) revealed that over $90 \%$ of the 'high-income countries' are not classified as being highly or very highly at risk, whereas almost $90 \%$ of the 'low-income countries' fall within these categories of risk and 50\% of the 'low-income countries' are 
only categorised as very high risk countries (see Table 2). With respect to sudden-onset hazards (Table 3), less than $25 \%$ of the 'high-income countries' are classified as high or very high risk, while by contrast more than $25 \%$ of the 'low-income countries' solely fall within the class of very high risk (see Table 3). Only 5\% of the 'high-income countries' face a high or very high risk of slow-onset hazards (Table 4). Yet, $90 \%$ of the 'low-income countries' are classified as being at high or very high risk with respect to slow-onset hazards (see Table 4). The differentiation of the WorldRiskIndex into the four income class categories of the World Bank clearly reveals that low-income and lower middle-income countries need to be seen as priority countries where the overall risk of being severely harmed and facing major loss and/or damage is significantly higher compared to that in high-income countries. In addition, the mapping of low-income countries that have a very high (red) WorldRiskIndex value also includes countries that face significant challenges in terms of governance and corruption, such as Mali or Niger. Consequently, addressing the risk of loss and damage particularly in low-income countries requires a critical re-examination of existing structures of governance and their inefficiencies or even failures such as those found in Niger and Chad. Furthermore, countries such as Mozambique that face significantly high WorldRiskIndex scores for slow- and sudden-onset hazards might need to be viewed as priority countries requiring resources and capacity-building for both sudden-onset shocks as well as strategies to address creeping hazards such as rising sea levels in the future.

Table 2 Percentiles of all countries at risk with respect to all climate-related hazards differentiated into World Bank income classes

\begin{tabular}{|c|c|c|c|c|c|c|c|c|}
\hline \multirow{2}{*}{\multicolumn{2}{|c|}{ World Bank classes }} & \multicolumn{7}{|c|}{ Percentile } \\
\hline & & \multirow{2}{*}{$\frac{5}{0.80}$} & \multirow{2}{*}{$\frac{10}{1.41}$} & \multirow{2}{*}{$\frac{25}{2.35}$} & \multirow{2}{*}{$\begin{array}{c}50 \\
3.34\end{array}$} & \multirow{2}{*}{$\frac{75}{4.10}$} & \multirow{2}{*}{$\begin{array}{c}90 \\
5.18\end{array}$} & \multirow{2}{*}{$\begin{array}{c}95 \\
9.80\end{array}$} \\
\hline Risk_All & $\mathrm{H}$ & & & & & & & \\
\hline & $\mathrm{L}$ & 5.33 & 6.39 & 7.20 & 8.51 & 11.04 & 12.75 & 17.90 \\
\hline & $\mathrm{LM}$ & 2.48 & 3.40 & 5.11 & 7.22 & 8.93 & 12.85 & 17.79 \\
\hline & UM & 2.79 & 3.44 & 3.94 & 4.84 & 6.21 & 7.36 & 10.57 \\
\hline
\end{tabular}

Notes: Risk values and respective percentiles are shown. These were analysed with the risk classes derived in Figure 5.

Table 3 Percentiles of all countries at risk with respect to sudden-onset climate-related hazards differentiated into World Bank income classes

\begin{tabular}{lcccccccc}
\hline \multirow{2}{*}{ World Bank classes } & \multicolumn{7}{c}{ Percentile } \\
\cline { 3 - 9 } & & 5 & 10 & 25 & 50 & 75 & 90 & 95 \\
\hline \multirow{2}{*}{ Risk_Sudde } & H & 0.0000 & 0.0006 & 0.0105 & 0.0703 & 0.1329 & 0.7041 & 2.6821 \\
& L & 0.0305 & 0.0427 & 0.0639 & 0.1003 & 0.5859 & 3.8735 & 9.6847 \\
& LM & 0.0000 & 0.0359 & 0.0783 & 0.1316 & 0.4645 & 3.7365 & 6.7942 \\
& UM & 0.0089 & 0.0194 & 0.0646 & 0.0890 & 0.1824 & 1.7388 & 3.4131 \\
\hline
\end{tabular}

Notes: Risk values and respective percentiles are shown. These were analysed with the risk classes derived in Figure 5. 
Table 4 Percentiles of all countries at risk with respect to slow-onset climate-related hazards differentiated into World Bank income classes

\begin{tabular}{lcccccccc}
\hline \multirow{2}{*}{ World Bank classes } & \multicolumn{7}{c}{ Percentile } \\
\cline { 3 - 9 } & & 5 & 10 & 25 & 50 & 75 & 90 & 95 \\
\hline Risk_Slow & H & 0.33 & 1.30 & 2.29 & 2.99 & 3.80 & 4.36 & 7.32 \\
& L & 4.98 & 6.26 & 6.71 & 7.71 & 9.81 & 11.36 & 12.21 \\
& LM & 1.62 & 3.14 & 4.78 & 7.01 & 7.95 & 10.88 & 11.26 \\
& UM & 2.76 & 3.26 & 3.83 & 4.64 & 5.67 & 6.36 & 7.30 \\
\hline
\end{tabular}

Notes: Risk values and respective percentiles are shown. These were analysed with the risk classes derived in Figure 5.

\section{Discussion of results and recommendations}

Overall, the risk analysis, based on the concept of the WorldRiskIndex and the socioeconomic country classes as defined by the World Bank, show that low-income and lower middle-income countries in general face a higher risk of being negatively affected by climate-related hazards, particularly as these relate to their higher vulnerability. In addition, the high rate of exposure to climate-related hazards globally are particularly evident in the Caribbean, the Sahel, parts of South-east Africa, South-east Asia and, in part, South-east Europe (see Figure 5). The differentiation between the four socioeconomic country classifications (World Bank income groups) and the slow- versus sudden-onset hazards in the context of climate change also reveal that countries in Africa are generally in a higher risk category, particularly in terms of slow-onset hazards, while the USA, for example, ranks relatively low in terms of their population's exposure to slow-onset hazards influenced by climate change (compared with global figures). By contrast, the USA is highly exposed to sudden-onset hazards compared to other regions and countries (red), and faces a medium total exposure which is composed of a low exposure to slow-onset hazards and a rather high exposure to sudden-onset hazards. Conversely, Zimbabwe has a very high total exposure with respect to slow-onset hazards, mainly due to droughts. However, comparing the high exposure of some countries to climate-related hazards does not necessarily mean that they are also facing a high risk. The risk of loss and damage is heavily determined by the societal vulnerability and the capacities of countries and communities to moderate and mitigate the potential negative impact of such hazards.

Working with indices can be criticised, since the selection of appropriate indicators, weighting and aggregation processes are well-known discussion points. Hence, the WorldRiskIndex was tested with respect to robustness and validity and revealed that the modelling approach of the index is reliable and the results are reasonable and robust. Therefore, this paper argues that the WorldRiskIndex is a valid approach to assess the risk of loss and damage and the results support the three different thematic areas of the UNFCCC. 


\subsection{Recommendations}

The results presented in the various maps and tables in this paper provide an estimate for and show interesting global distribution patterns of peoples' exposure to climate-related hazards and the vulnerability of the respective populations. These numbers are not intended to provide very specific information on the detailed risk patterns for individual countries; rather, they provide an overview of knowledge and show that the risk of loss and damage in the context of climate change differs significantly between and even within different income groups, while slow- and sudden-onset hazards create quite different global risk distributions.

First, the results of the modified WorldRiskIndex underscore that the least developed in particular and developing countries in general must be seen as priorities in risk reduction and adaptive strategies to reduce the risk of loss and damage in the context of climate-related hazards. However, the findings also show that countries in transition such as Vietnam need to prepare for and deal with significant risks due to climate change at present and even more so in the future. This is particularly the case with regard to sea level rise and increasing population concentrations along coastal zones for example. Consequently, strategies and institutional mechanisms for addressing the risk of loss and damage should not be focused solely on the least developed or developing countries, but also on countries in transition which are highly at risk.

Second, various countries in Africa and some in Asia, especially South-east Asia, face a high level of poverty, which contributes significantly to a high level of vulnerability or a low coping capacity. These countries also show significant deficits in terms of governance structures and in terms of the challenges of corruption (see Table 5).

Table 5 The average scores for the corruption perception index (scale of 0 to 10 , where 0 is the highest perceived corruption level and 10 is the least perceived corruption level) and the failed state index (scale of 0 to 120 , where 0 is the most stable state and 120 is the most critical) with respect to all top 10 countries listed in Tables 2-5

\begin{tabular}{lcccc}
\hline Governance indicators & $\begin{array}{c}\text { Top 10 } \\
\text { low-income } \\
\text { countries }\end{array}$ & $\begin{array}{c}\text { Top 10 } \\
\text { lower } \\
\text { middle-income } \\
\text { countries }\end{array}$ & $\begin{array}{c}\text { Top 10 } \\
\text { upper } \\
\text { middle-income } \\
\text { countries }\end{array}$ & $\begin{array}{c}\text { Top 10 } \\
\text { high-income } \\
\text { countries }\end{array}$ \\
\hline $\begin{array}{l}\text { Average corruption } \\
\text { perception index }\end{array}$ & 2.5 & 3.2 & 3.5 & 6.1 \\
Average failed state index & 93.2 & 80.5 & 72.2 & 47.4 \\
\hline
\end{tabular}

This means that strategies to address the risk of loss and damage need to encompass measures for identifying and, if feasible, reducing climate-related hazards as well as reducing societal vulnerability. Among other issues in various countries in Africa as well as in select countries in South-east Asia, reducing vulnerability and improving the capacity to cope also require improvements in governance, reducing corruption and enhancing coping mechanisms. Examples include improvements in the coverage of health and other insurance mechanisms against specific hazards, particularly for the most vulnerable groups. 
Third, risk assessments point to the fact that some low-income countries at high risk, such as Bangladesh, Cambodia, Guinea-Bissau or Haiti, face severe limitations in reducing their exposure to climate-related hazards such as sea-level rise due to their limited financial capability, for example, to reinforce and construct protective infrastructure. Consequently, in these countries, improvements need to be fostered through adaptation funds and strategies in the area of coping and adaptive capacities. In particular, if the national-level system such as that in Haiti faces severe constraints in providing support for building coping and adaptive capacities of people at risk, adaptation funding should not be solely targeted to national-level institutions. In addition, conventional strategies for risk management and adaptation might fall short in addressing the challenges of exposure reduction; hence, new concepts must be developed which are particularly tailored to low-income countries with a high level or rapidly increasing levels of exposed populations to creeping hazards such as sea-level rise. In terms of coping capacities and economic coverage through insurance, it is also important to note that, even though the absolute economic damages are significantly higher in high-income countries, various countries are also characterised by a relatively high level of insurance coverage. This means that, in contrast to low-income countries, people and enterprises in high-income countries might receive significant compensation for their experienced losses due to their insurance coverage, while insurance coverage is significantly lower in low- and lower middle-income countries (Linnerooth-Bayer, 2012).

Overall, the selected results presented in this paper using a modified version of the WorldRiskIndex methodology demonstrate that present negotiations for a new mechanism and institutional structures to address loss and damage cannot usefully be limited to actual loss and damage. Instead, they must address the risk of loss and damage that also accounts for factors that potentially increase risk accumulation and the vulnerability of societies to suffer harm due to extreme events.

Furthermore, based on the findings from empirical analysis, the authors recommend that mechanisms to address loss and damage should also be developed at least along three different categories:

1 different climate-related hazard types (sudden-onset versus creeping)

2 different socio-economic country classifications

3 groups of countries with severe governance challenges.

All of these categories encompass quite different global risk distribution patterns that should be acknowledged within various adaptation and risk reduction programs. Simply focusing on least-developed countries and national-level adaptation programs will not provide a vehicle to address the risk of loss and damage adequately. An improved consideration of the different determinants of risk and risk profiles linked to, for example, different hazard types, country income classifications and governance challenges is a prerequisite in order to move from the general monitoring and treatment of past and present loss and damage patterns to the anticipation of risks through effective and specific adaptation program structures. 


\section{References}

Birkmann, J. (2013) 'Measuring vulnerability to promote disaster-resilient societies: conceptual frameworks and definitions', in Birkmann, J. (Ed.): Measuring Vulnerability to Natural Hazards: Towards Disaster Resilient Societies, 2nd ed., pp.9-80, United Nations University, New York.

Birkmann, J., Buckle, P., Jaeger, J., Pelling, M., Setiadi, N., Garschagen, M., Fernando, N. and Kropp, J. (2010) 'Extreme events and disasters: a window of opportunity for change? Analysis of organizational, institutional and political changes, formal and informal responses after mega-disasters', Natural Hazards, Vol. 55, No. 3, pp.637-669.

Birkmann, J., Cutter, S., Rothman, D., Welle, T., Garschagen, M., van Ruijven, B., O‘Neill, B., Prestion, B.L., Kienberger, S., Cardona, O.C., Siagin, T., Hidayati, D., Stetiadi, N., Binder, C., Hughes, B. and Pulwarty, R. (2013) 'Scenarios for vulnerability: opportunities and constraints in the context of climate change and disaster risk', Climatic Change, DOI 10.1007/s10584013-0913-2 [online] http://link.springer.com/article/10.1007/s10584-013-0913-2 (accessed 23 August 2013).

Birkmann, J., Welle, T., Krause, D., Wolfertz, J., Suarez, D.C. and Setiadi, N. (2011) WorldRiskIndex: Concept and Results, WeltRisikoBericht (Ed.), pp.S.13-43, Bündnis Entwicklung Hilft, Berlin.

Burton, I., Kates, R.W. and White, G.F. (1993) The Environment as Hazard, 2nd ed., Guildford Press, New York.

Center for International Earth Science Information Network (CIESIN), Columbia University; International Food Policy Research Institute (IFPRI), The World Bank, and Centro Internacional de Agricultura Tropical (CIAT) (2012) Global Rural-Urban Mapping Project (GRUMP): Population Count Grid for 2010 (Alpha), NASA Socioeconomic Data and Applications Center (SEDAC), Columbia University, Palisades, NY.

Center for Remote Sensing of Ice Sheets (CReSIS), University of Kansas (2011) Sea Level Rise Maps, Lawrence, KS.

Economic Commission for Latin America and the Caribbean (ECLAC) (2003) Handbook for Estimating the Socio-economic and Environmental Effects of Disasters LC/MEX/G.5 LC/L.1874 [online] http://www.eclac.cl/publicaciones/xml/4/12774/lcmexg5i_VOLUME_ Ia.pdf (accessed 24 August 2013).

Emergency Management Agency (EMA) (2002) Australian Emergency Manuals Series. Part III. Emergency Management Practice. Volume 3 - Guidelines. Guide 11. Disaster Loss Assessment Guidelines, Queensland Government, Department of Emergency Services and Emergency Management Australia (Handmer, J., Read, C. and Percovich, O.).

Handmer, J., Abrahams, J., Betts, R. and Dawson, M. (2005) 'Towards a consistent approach to disaster loss assessment across Australia', The Australian Journal of Emergency Management, February, Vol. 20, No. 1 [online] http://www.ema.gov.au/www/emaweb/rwpattach.nsf/VAP/ (99292794923AE8E7CBABC6FB71541EE1) Towards+a+consistent+approach+to+disaster+ loss+assessment.pdf/\$file/Towards+a+consistent+approach+to+disaster+loss+assessment.pdf (accessed 24 August 2013).

Instituto de Estudios Ambientales (IDEA) (2005) Indicators of Disaster Risk and Risk Management: Main Technical Report, IADB/IDEA Program of Indicators for Disaster Risk Management, Universidad Nacional de Colombia, Manizales.

International Federation of the Red Cross and Red Crescent Societies (2008) Guidelines for Assessment in Emergencies [online] http://www.icrc.org/eng/assets/files/publications/icrc-002118009.pdf (accessed 23 August 2013). 
IPCC (2012) Summary for Policymakers. Managing the Risks of Extreme Events and Disasters to Advance Climate Change Adaptation, Field, C.B., Barros, V., Stocker, T.F., Qin, D., Dokken, D.J., Ebi, K.L., Mastrandrea, M.D., Mach, K.J., Plattner, G-K., Allen, S.K., Tignor, M. and Midgleyand, P.M. et al. (Eds.), A Special Report of Working Groups I and II of the Intergovernmental Panel on Climate Change, pp.1-19, Cambridge University Press, Cambridge, UK, and New York.

IPCC (2014) Summary for Policymakers, in Field, C.B., V.R. Barros, D.J. Dokken, K.J. Mach, M.D. Mastrandrea, T.E. Bilir, M. Chatterjee, K.L. Ebi, Y.O. Estrada, R.C. Genova, B. Girma, E.S. Kissel, A.N. Levy, S. MacCracken, P.R. Mastrandrea and L.L. White (Eds.): Climate Change 2014: Impacts, Adaptation, and Vulnerability, Contribution of Working Group II to the Fifth Assessment Report of the Intergovernmental Panel on Climate Change, pp.1-32, Cambridge University Press, Cambridge, UK and New York, NY, USA.

Lavell, A., Oppenheimer, M., Diop, C., Hess, J., Lempert, R., Li, J., Muir-Wood, R. and Myeong, S. (2012) 'Climate change: new dimensions in disaster risk, exposure, vulnerability, and resilience’, in Field, C.B., Barros, V., Stocker, T.F., Qin, D., Dokken, D.J., Ebi, K.L., Mastrandrea, M.D., Mach, K.J., Plattner, G-K., Allen, S.K., Tignor, M. and Midgley, P.M. (Eds.): Managing the Risks of Extreme Events and Disasters to Advance Climate Change Adaptation, A Special Report of Working Groups I and II of the Intergovernmental Panel on Climate Change (IPCC), pp.25-64, Cambridge University Press, Cambridge, UK, and New York, NY, USA.

Linnerooth-Bayer, J. (2012) Loss and Damage from Weather Variability. The Role of Risk Sharing and Transfer, International Institute for Applied Systems Analysis, Luxemburg, Austria [online] http://www.climate-insurance.org/upload/pdf/20120325_Tokyo_mtg_ LinneroothBayer_the_role_of_risk_sharing_and_transfer_in_addressing_loss_and_damage_fr om_weather_variability.pdf (accessed 24 August 2013).

Peduzzi, P., Dao, H., Herold, C. and Mouton, F. (2009) 'Assessing global exposure and vulnerability towards natural hazards: the disaster risk index', Natural Hazards and Earth System Sciences, Vol. 9, No. 4, pp.1149-1159.

Reb, J., Iinuma, Y. and Joshi, H. (2012) The Fukushima Nuclear Disaster: Causes, Consequences and Implications, Case Collection, Paper 28.

UN/ISDR (International Strategy for Disaster Reduction) (2004) Living with Risk: A Global Review of Disaster Reduction Initiatives, 2004 Version, UN Publications, Geneva.

UNFCCC (2011a) Decision 1/CP.16: Report of the Conference of the Parties on its Sixteenth Session, held in Cancun from 29 November to 10 December 2010, Addendum Part Two: Action taken by the Conference of the Parties at its Sixteenth Session Outcome of the Work of the Ad Hoc Working Group on Long-term Cooperative Action under the Convention, FCCC/CP/2010/7/Add.1.

UNFCCC (2011b) Draft Decision -/CP.17: Outcome of the Work of the Ad Hoc Working Group on Long-term Cooperative Action under the Convention/Work Programme on Loss and Damage, $-/$ CP.17

UNFCCC (2012) Current Knowledge on Relevant Methodologies and Data Requirements as well as Lessons Learned and Gaps Identified at Different Levels in Assessing the Risk of Loss and Damage Associated with the Adverse Effects of Climate Change, Technical Paper 12/1, Bonn [online] http://unfccc.int/resource/docs/2012/tp/01.pdf.

Welle, T., Birkmann, J., Krause, D., Suarez, D.C., Setiadi, N. and Wolfertz, J. (2013) 'The WorldRiskIndex: a concept for the assessment of risk and vulnerability at global/national scales', in Birkmann, J. (Ed.): Measuring Vulnerability to Natural Hazards: Towards Disaster Resilient Societies, 2nd ed., pp.219-251, United Nations University, New York.

Welle, T., Birkmann, J., Rhyner, J., Witting, M. and Wolfertz, J. (2012) 'WorldRiskIndex 2012: concept, updating and results', WorldRiskReport 2012, pp.11-27, HRSG, Bündnis Entwicklung Hilft, Aachen, Germany.

Wisner, B., Blaikie, P., Cannon, T. and Davis, I. (2004) At Risk: Natural Hazards, People's Vulnerability and Disasters, Routledge, London. 
World Bank (2013) GNI per Capita, Atlas Method (Current US\$) [online] http://data.worldbank.org/indicator/NY.GNP.PCAP.CD (accessed 24 August 2013).

\section{Notes}

1 The following section is based on a technical paper written for the climate change negotiations from the United Nations Framework Convention on Climate Change's program on loss and damage, which the authors co-wrote (see UNFCCC, 2012).

\section{Appendix}

Figure S1 Country groups based on World Bank classification (see online version for colours)

\section{Country groups based on World Bank classification}

Data based on GNI per capita in US\$ (atlas method)

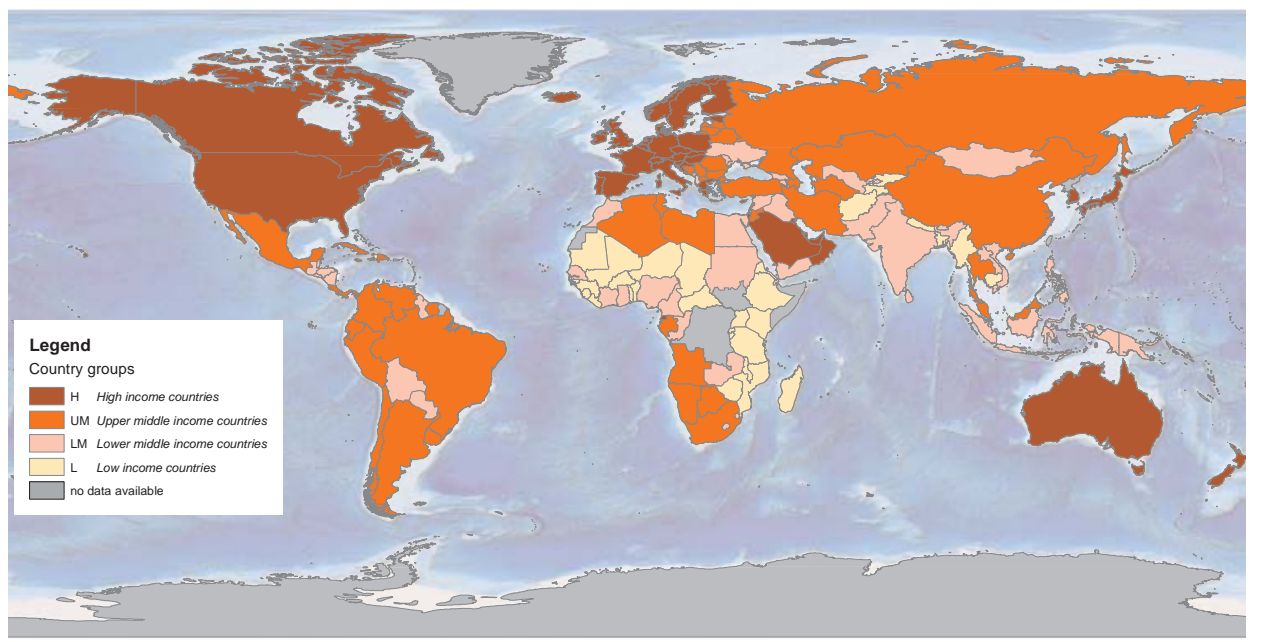

Note: Indicator used is GNI per capita in US dollars (Atlas method). 
Figure S2 (a) Exposure towards climate related hazards (floods, storms, droughts, sea level rise) combined with (b) vulnerability results in (c) WorldRiskIndex (see online version for colours)

\section{Exposure}

Exposure of the population to climate related natural hazards (storms, floods, droughts and sea level rise)

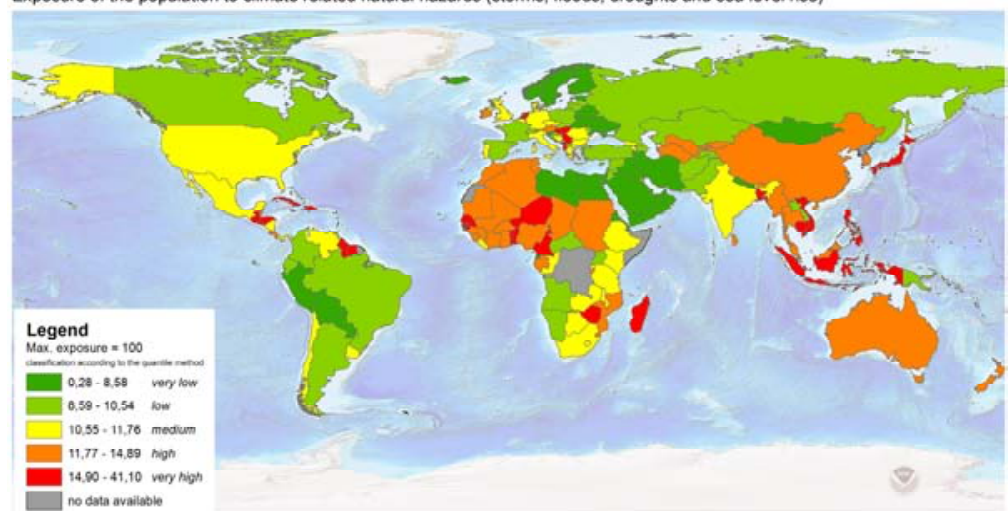

(a)

Vulnerability

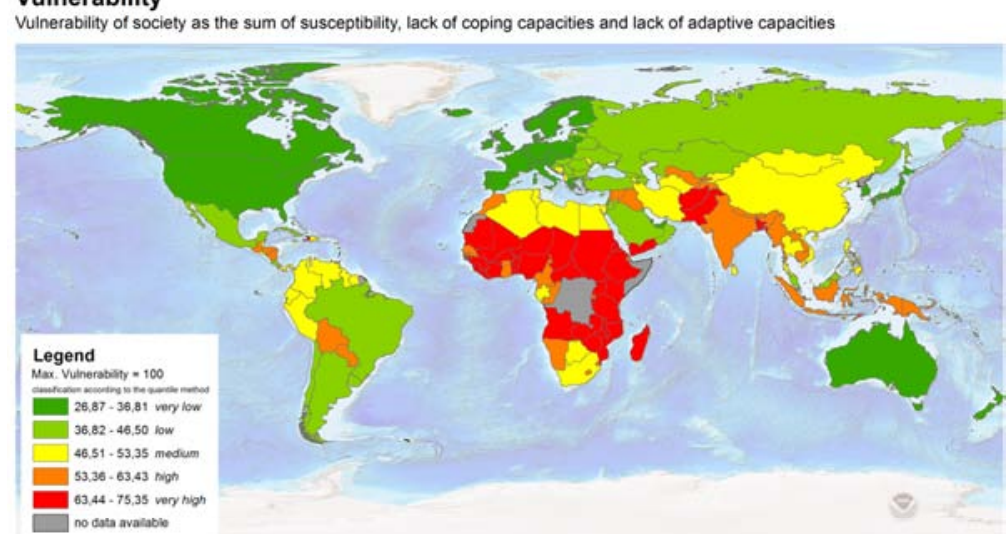

(b)

WorldRisklndex (climate related hazards)

WorldRiskindex as a res

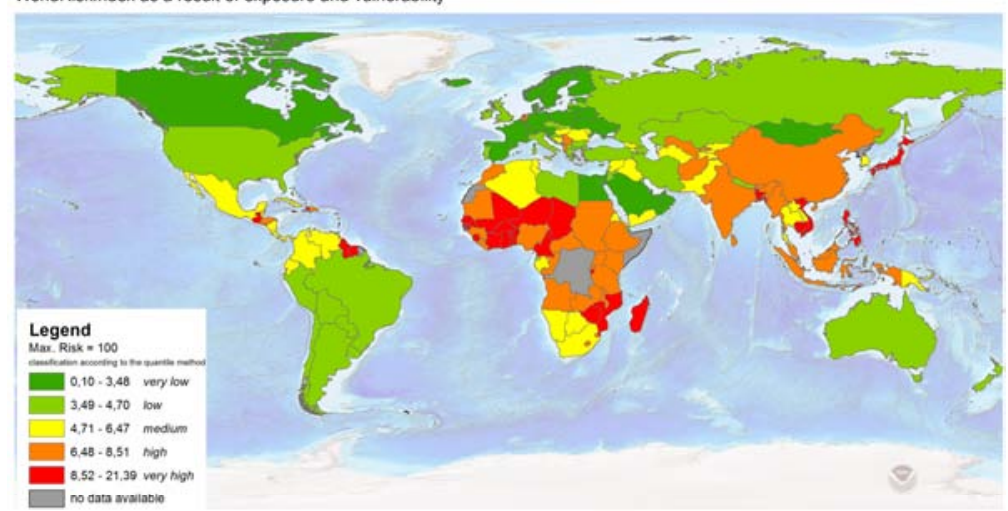

(c) 
Figure S3 Climate-related risk in the upper middle income (top) and lower middle income (bottom) country groups differentiated in slow-onset hazards (left) and sudden-onset hazards (right) (see online version for colours)
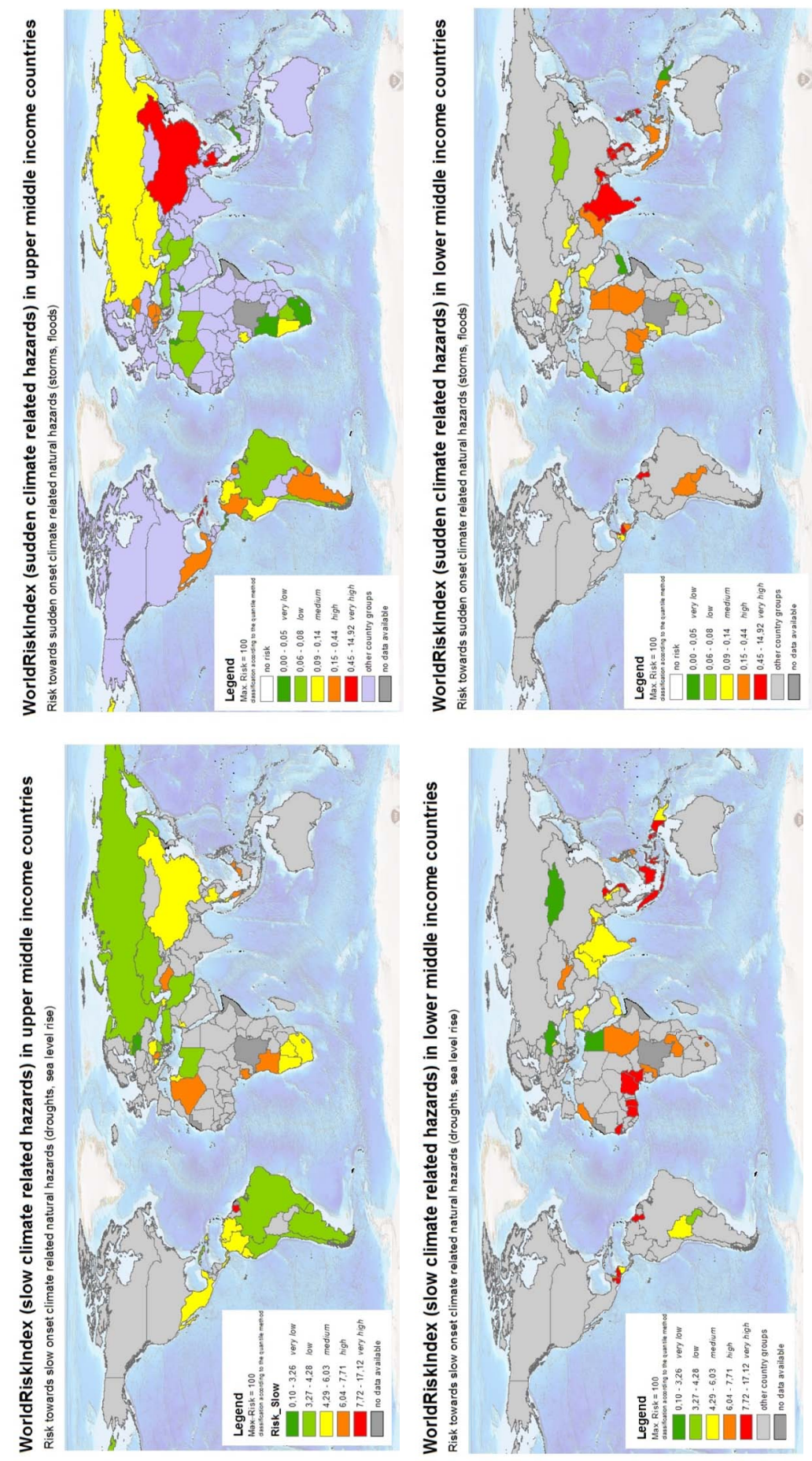